\title{
Hypertension and Management
}

Open Access

RESEARCH ARTICLE

\section{Nigerian Citrullus Lanatus Fruit and Seed Juice Reduces Cardio- vascular Diseases Modifiable Risk Biomarkers in Normal Experi- mental Rats}

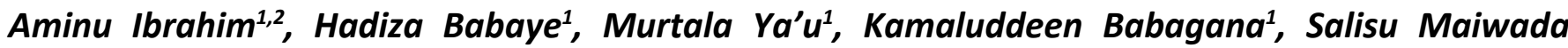 \\ Abubakar ${ }^{1}$, Jamila Mashi Ahmad ${ }^{1}$ and Abba Babandi ${ }^{*}$ \\ ${ }^{1}$ Department of Biochemistry, Bayero University, Nigeria \\ ${ }^{2}$ Department of Biochemistry, Ahmadu Bello University, Nigeria
}

*Corresponding author: Abba Babandi, Department of Biochemistry, Bayero University, PMB 3011, Kano, Nigeria, Tel: $+2348086303170$

\begin{abstract}
Dyslipidemia and imbalance of electrolytes are among the modifiable risk factors for cardiovascular diseases (CVDs) which cause morbidity and mortality in hypertensive patients. Consumption of fruits and their juices has been shown to be beneficial health wise by lowering risk of coronary artery/cardiovascular diseases, stroke and other degenerative diseases. The lowering effects and protective mechanism of these fruits are probably due to numerous beneficial nutrients and extra-nutrients found in these fruits, such as mono- and poly-unsaturated fatty acids, antioxidant vitamins, secondary plant products, digestive fiber, mineral elements (such as calcium and magnesium), plant proteins and peptides. This preliminary study is aimed at determining the effect of Citrullus lanatus fruit and seed juice on some cardiac enzymes, lipid profile, and electrolytes in normal albino rats. Twenty rats were divided into four groups of five each; a control and three experimental groups. The three experimental groups were given respectively, the doses of $1.7 \mathrm{~g}, 3.4 \mathrm{~g}$, and 6.8 $\mathrm{g}$ per $\mathrm{kg}$ of body weight daily for 14 days. Serum Aspartate Aminotransferase (AST), Creatine kinase (CK), Lactate Dehydrogenase (LDH), total cholesterol (TC), triglyceride (TG), high-density lipoproteins (HDL-C), low-density lipoproteins (LDL-C), potassium and sodium were determined. The results showed significant decrease $(P<0.05)$ in the levels of Creatine kinase between the test groups $(3.4 \mathrm{~g} / \mathrm{kg}$ and $6.8 \mathrm{~g} /$ $\mathrm{kg})$, triglycerides and LDL-C between the test groups $(1.7 \mathrm{~g} /$ $\mathrm{kg}$ and $6.8 \mathrm{~g} / \mathrm{kg}$ ) and also sodium between the test groups $(1.7 \mathrm{~g} / \mathrm{kg}$ and the other two $3.4 \mathrm{~g} / \mathrm{kg}$ and $6.8 \mathrm{~g} / \mathrm{kg})$. Also, significant increase $(P<0.05)$ was observed in LDH levels between the test groups $(3.4 \mathrm{~g} / \mathrm{kg}$ and $6.8 \mathrm{~g} / \mathrm{kg})$, triglycerides levels between the control and test groups $(1.7 \mathrm{~g} / \mathrm{kg}$ and 3.4 $\mathrm{g} / \mathrm{kg}$ ), LDL-C levels between the control and test group $(1.7 \mathrm{~g} /$ $\mathrm{kg}$ ) and sodium levels between the control and the test group
\end{abstract}

(1.7 g/kg). Serum AST, TC, HDL-C and potassium levels were not affected significantly. The significant decreases in CK, TG, LDL-C, and sodium, suggest that consumption of extract from a blend of seed and pulp of Citrullus lanatus fruits may have cardiovascular disease risk decreasing potential at the doses administered.

\section{Keywords}

Citrullus lanatus, Cardiovascular disease, Lipid profile, Cardiac enzymes, Electrolytes

\section{Introduction}

Cardiovascular disease (CVD) is a class of diseases that involve the heart or blood vessels (arteries, capillaries, and veins) and its leading cause of morbidity-mortality in developing and developed countries [1,2]. Cardiovascular diseases are diverse (which includes Coronary Heart Disease (CHD), cerebrovascular disease and peripheral vascular disease etc.). but atherosclerosis and hypertension are the most common. Others include chronic heart failure, cardiac arrhythmias, thrombosis and dyslipidaemia [3]. Dyslipidaemia is associated with abnormally high levels of total cholesterol (TC) and low-density lipoproteins cholesterol (LDL-C) and/ or abnormally low levels of high-density lipoproteins cholesterol (HDL-C), as well as disorders in the composition of various lipoprotein particles. The parameters such as LDL-C, TC etc. are of significant importance to man's health because they are directly associated with

Citation: Ibrahim A, Babaye H, Ya'u M, Babagana K, Abubakar SM, et al. (2018) Nigerian Citrullus Lanatus Fruit and Seed Juice Reduces Cardiovascular Diseases Modifiable Risk Biomarkers in Normal Experimental Rats. J Hypertens Manag 4:036. doi.org/10.23937/2474-3690/1510036

Accepted: September 10, 2018: Published: September 12, 2018

Copyright: (C) 2018 Ibrahim A, et al. This is an open-access article distributed under the terms of the Creative Commons Attribution License, which permits unrestricted use, distribution, and reproduction in any medium, provided the original author and source are credited. 
the risk of hypertension, which can triple the risk of heart attacks and which is a well-established risk factor for CVD $[4,5]$. Dyslipidemia is one of the major cardiovascular risk factors and may be secondary to disorders such as obesity, diabetes mellitus, hypothyroidism and nephrotic syndrome [3]. Hypertension is a sustained systolic blood pressure of more than $140 \mathrm{mmHg}$ and/or diastolic blood pressure of more than $90 \mathrm{mmHg}$. It is a major risk factor for coronary heart disease and stroke [6]. Fruits and vegetables are a group of heterogeneous foods with different level of vitamins, minerals, and other bioactive products. Watermelon (Citrullus lanatus) is considered one of the high lycopene foods. Lycopene is a carotenoid phytonutrient that is especially important for cardiovascular health among others [7,8]. Generally, lifestyles are the most important determinants of CVD, among which nutritional habits play an important role. Higher dietary fiber intake has been recognized to be inversely associated with coronary heart disease (CHD) [9] and stroke [10].

Health scientists are becoming more interested in citrulline content of watermelon. Citrulline is an important amino acid that is commonly converted by the kidneys and another organ system into arginine (another amino acid). A higher level of arginine can help improve blood flow and other aspects of the cardiovascular health. It also helps to prevent excess accumulation of fat in fat cells due to the blocked activity of an enzyme called tissue non-specific alkaline phosphatase [11].

Phenolic compounds in watermelon which include flavonoids, carotenoids and triterpenoids make this fruit a choice for anti-inflammatory and anti-oxidant health benefits [12]. Watermelon gets its reddish-pink shades primarily from lycopene. Lycopene in watermelon is a well-documented inhibitor of many inflammatory processes including the production of pro-inflammatory messaging molecules, the expression of enzymes like cyclo-oxygenase and lipoxygenase that can lead to increased inflammatory response and activity of molecular signaling agents like nuclear factor kappa B (NF-kB). Lycopene is also a well-known antioxidant with the ability to neutralize free radical molecules [13].

An enzyme called nitric oxide synthase (NOS) found in many of the body cell types is able to take the amino acid Arginine and use it to produce a very small molecule of gas called nitric oxide, which is a muscle relaxant. For example, when nitric oxide causes the smooth muscle around the blood vessels to relax, the space inside the blood vessel can expand, allowing blood to follow more freely and creating a drop-in blood pressure [13]. Assessing and monitoring of modifiable risk factors can be vital to reducing CVD-associated morbidity and mortality in developing countries. This study is, therefore, aimed at determining the effect of Citrullus lanatus fruit and seed juice obtained from Nigeria market on some cardiovascular disease risk markers in normal albino rats.

\section{Materials and Methods}

\section{Fruit collection and authentication}

Fresh ripened watermelon fruit was obtained from local dealers in a well-known fruit market called 'Yan Lemo Na'ibawa in Kano State Nigeria. The fruit was then authenticated by a botanist in the Department of Plant Science, Bayero University Kano, Nigeria.

\section{Preparation of juice}

The method for juice preparation adopted by Erifeta, et al. [14] was used with little modification. A whole watermelon was peeled and the red pulp including the seeds was cut into slices, weighed and homogenized in a blender to obtain a juice. The juice of the Citrullus lanatus fruit and seed was then administered to the rats orally.

\section{Experimental animals, design and treatment}

A total of twenty albino rats of the Wistar strain (average $110 \mathrm{~g}$ each) were obtained from the animal house of the Department of Zoology Bayero University Kano, Nigeria. The rats were kept in a clean and dry iron cage with twelve hours of light and dark cycle at $25 \pm 2{ }^{\circ} \mathrm{C}$. The animals were fed with pellets obtained from Grand Cereals Nigeria Limited, Jos, Plateau State, Nigeria. Food and water were given ad libitum [15]. The administration of juice was done using $120 \mathrm{~g} / 70 \mathrm{~kg}$ body weight as standard dose, which is equivalent to $1.7 \mathrm{~g} / \mathrm{kg}$ for the rats. The rats were divided into four groups of five rats each. Group I served as control and were given distilled water, Group II was given the normal dose of watermelon blend, Group III was given 2 times of the normal dose of watermelon blend, and group IV were given 4 times normal dose of watermelon blend. The juice was administered orally daily for two weeks. Rats were sacrificed at the end of the treatment and blood collected for analysis of CVD risk markers [15].

\section{Determination of serum electrolytes}

Serum potassium: The amount of potassium was determined in serum by using sodium tetraphenyl boron in a specially prepared mixture to produce a colloidal suspension, the turbidity of which is proportional to potassium concentration in the range $2-7 \mathrm{mEq} / \mathrm{L}$ [16].

Serum sodium: Serum sodium was determined by the modified method of Maruna [17] and Trinder [18] in which sodium is precipitated as the triple salt, sodium-magnesium uranyl acetate, with the excess uranium then being reacted with ferrocyanide, producing a chromophore whose absorbance varies inversely as the concentration of sodium in the test sample.

Serum cholesterol (Enzymatic endpoint method): The cholesterol was determined after the enzymatic hydrolysis and oxidation (Enzymatic commercial test Kits obtained from Randox Company). The indicator quinoneimine was formed from hydrogen peroxide and 4-amino antipyrine in 
the presence of phenol and peroxidase.

Cholesterolester $+\overrightarrow{\text { Watercholesteol esterase Cholesterol }}+$ FattyAcid

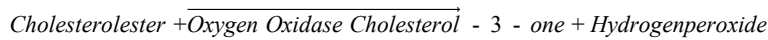

2 Hydrogenperoxide + Phenol $+4-\overrightarrow{a \text { min oantipyrine Peroxidase Quinonei } \min e}+$ Water

Serum Triglycerides (GPO-PAP METHOD) [19].

Serum HDL- Cholesterol [20].

\section{Low-density lipoprotein (LDL)}

The Concentration of LDL was obtained by LDL Conc. $=\mathrm{T}$. Chol $-\mathrm{HDL}+\mathrm{Trig} / 2.2$.

\section{Determination of cardiac enzymes}

Serum Aspartate Aminotransferase (AST) was determined by Reitman and Frankel, [21]; Serum Lactate
Dehydrogenase (LDH) was determined [22] and Serum Creatine Kinase-MB, was by Abbott, [23] and Gephardt [24] methods.

\section{Formulation of experimental dosage}

The experimental dose of this study was calculated based on the individual consumption of watermelon per day and the result was extrapolated to the animals, based on the average group weight. The doses are 1.7 $\mathrm{mg} / \mathrm{kg}, 3.4 \mathrm{mg} / \mathrm{kg}, 6.8 \mathrm{mg} / \mathrm{kg}$ C. lanatus.

\section{Statistical analysis}

Data are presented as mean \pm SEM (Standard Error of the Mean). Comparisons were made between the groups by the use of Student's t-test. All data were an-

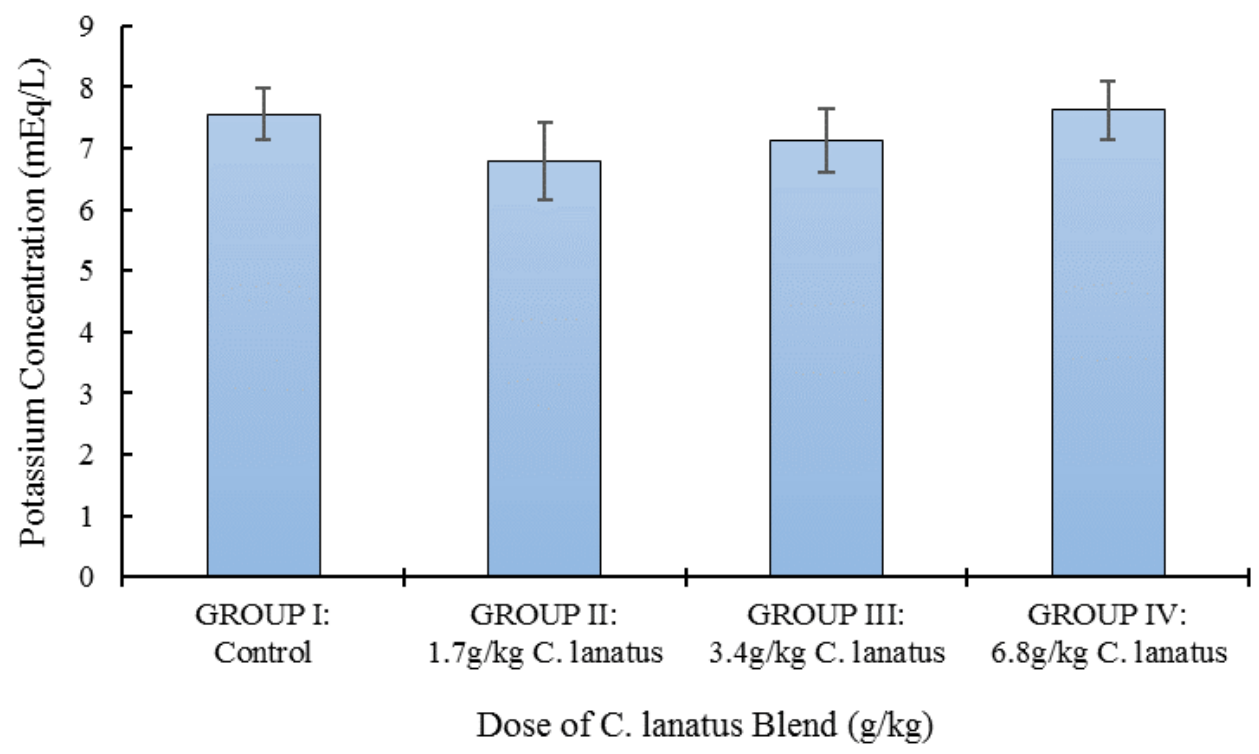

Figure 1: Serum Potassium Concentration of Albino (Wistar) Rats orally administered with a different dose of $C$. lanatus juices. Values are expressed as the mean \pm standard error $(n=5)$. Values with the same later are statistically significant at $P<0.05$.

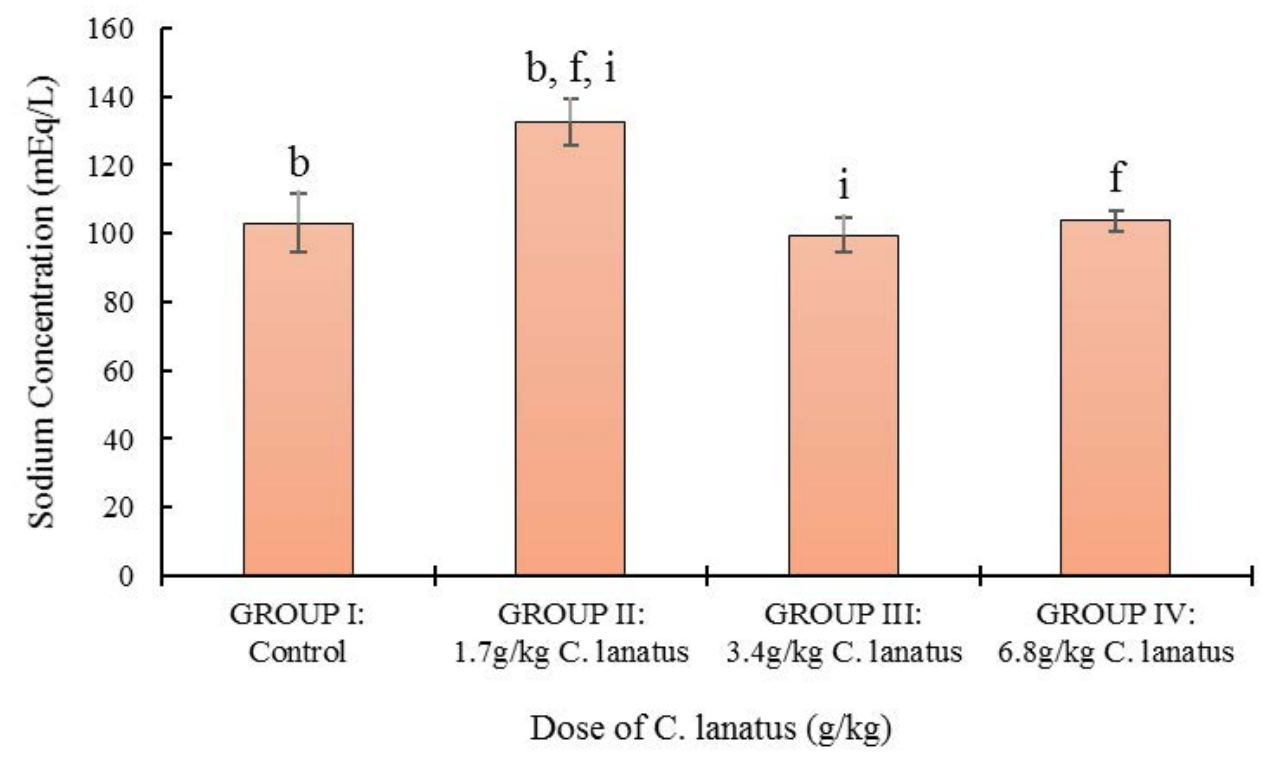

Figure 2: Serum Sodium Concentration of Albino (Wistar) Rats orally administered with a different dose of $C$. lanatus juices. Values are expressed as the mean \pm standard error $(n=5)$. Values with the same later are statistically significant at $P<0.05$. 
alyzed using SPSS version 17.0 (Chicago, IL), with values having $\mathrm{P}<0.05$ considered significant.

\section{Results and discussion}

The hypolipidemic, electrolytes and cardiac enzymatic effect of $C$. lanatus fruit juice in normal albino rats was determined and the results were presented in the figures.

In Figure 1; serum potassium showed no significant increased between the study groups $(P>0.05)$.

Figure 2 shows a significant $(P<0.05)$ increase in sodium levels between the control and the test group administered $1.7 \mathrm{~g} / \mathrm{kg}$, but there was a significant decrease in the sodium level between the group adminis- tered $1.7 \mathrm{~g} / \mathrm{kg}$ and the other two groups administered $3.4 \mathrm{~g} / \mathrm{kg}$ and $6.8 / \mathrm{kg}$ respectively.

There was also significant $(P<0.05)$ decrease in Creatine kinase and significant increase of LDH $(P<0.05)$ between the test group administered $3.4 \mathrm{~g} / \mathrm{kg}$ and that group administered $6.8 \mathrm{~g} / \mathrm{kg}$ only. Other parameters did not alter significantly $(P>0.05)$ (Figure 3 ).

There was a significant $(P<0.05)$ increase in triglyceride level between the control group and the test groups administered $1.7 \mathrm{~g} / \mathrm{kg}$ and $3.4 \mathrm{~g} / \mathrm{kg}$ while a decreased level was seen between the group administered $1.7 \mathrm{~g} /$ $\mathrm{kg}$ and the one administered $6.8 \mathrm{~g} / \mathrm{kg}$ (Figure 4).

A significant increase in LDL levels was obtained between the control group and the group administered

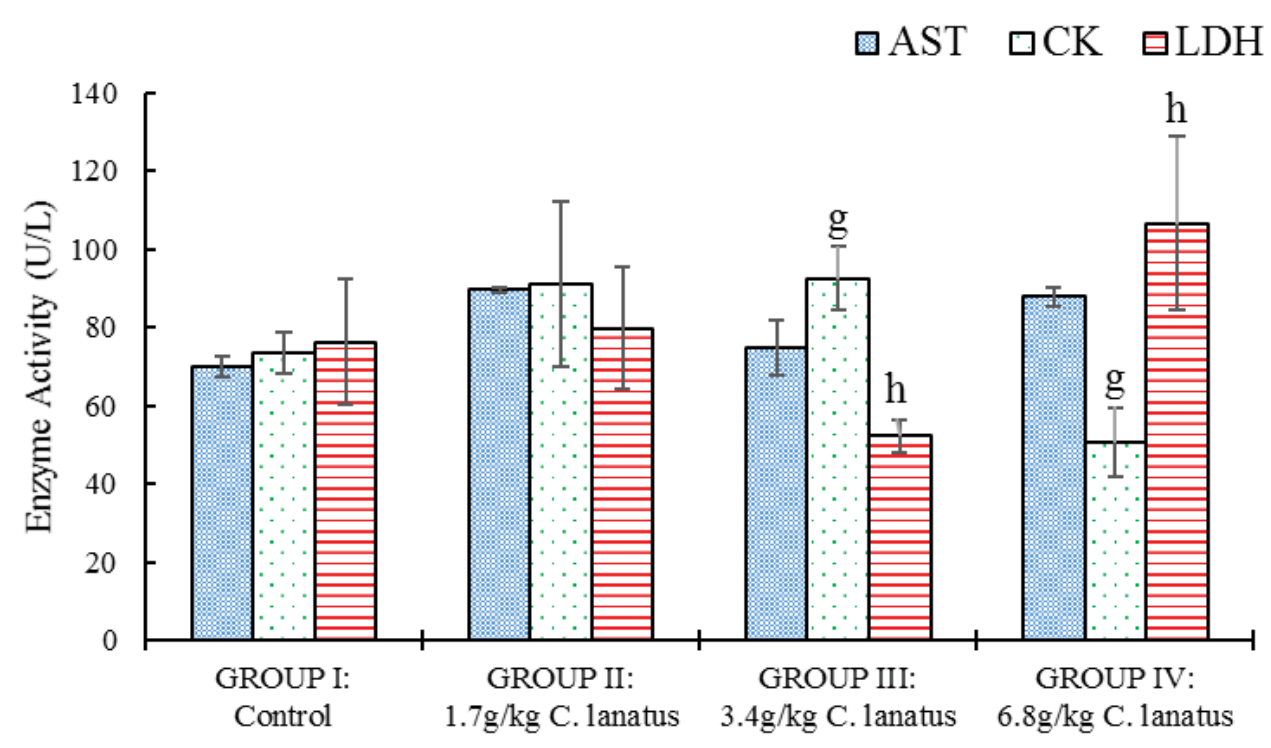

Figure 3: Serum Cardiac Enzymes Activity of Albino (Wistar) Rats orally administered with a different dose of $C$. lanatus juices. Values are expressed as mean \pm standard error $(n=5)$ Values with the same later are statistically significant at $P<0.05$.

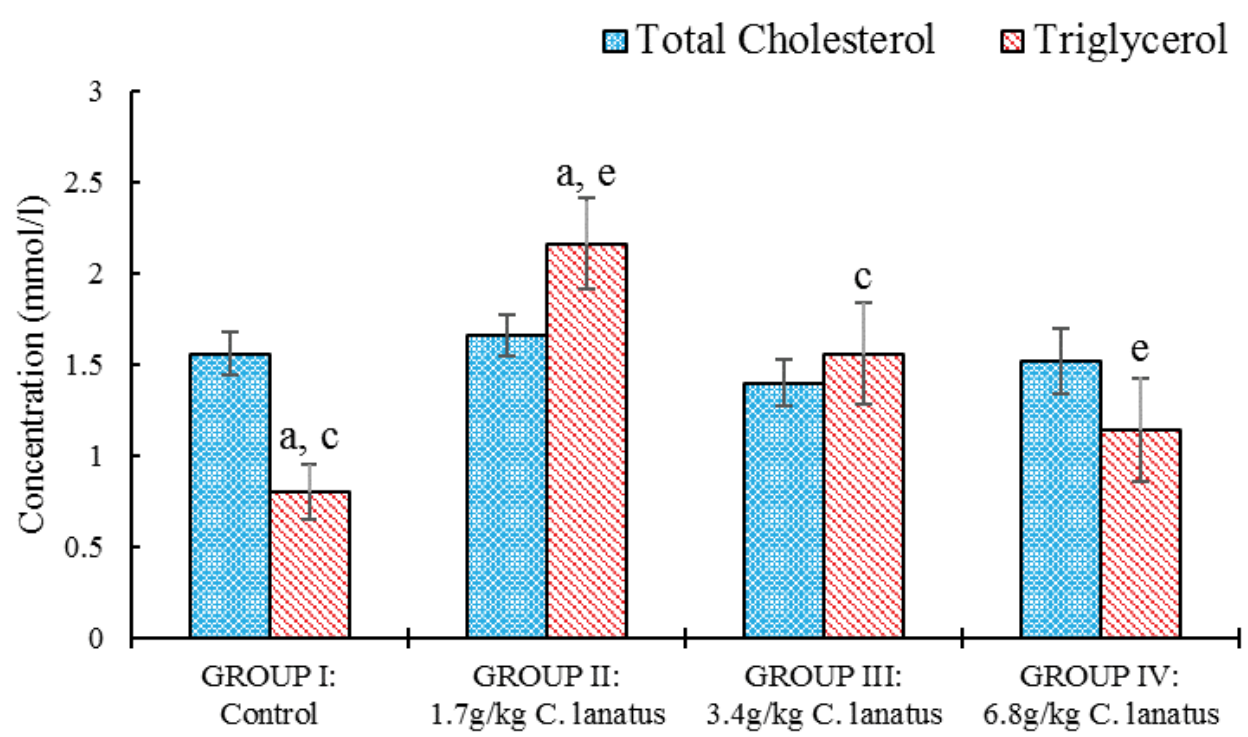

Figure 4: Serum Total Cholesterol and Triglycerol of Albino (Wistar) Rats orally administered with a different dose of $C$. lanatus juices. Values are expressed as the mean \pm standard error $(n=5)$. Values with the same later are statistically significant at $\mathrm{P}<0.05$. 


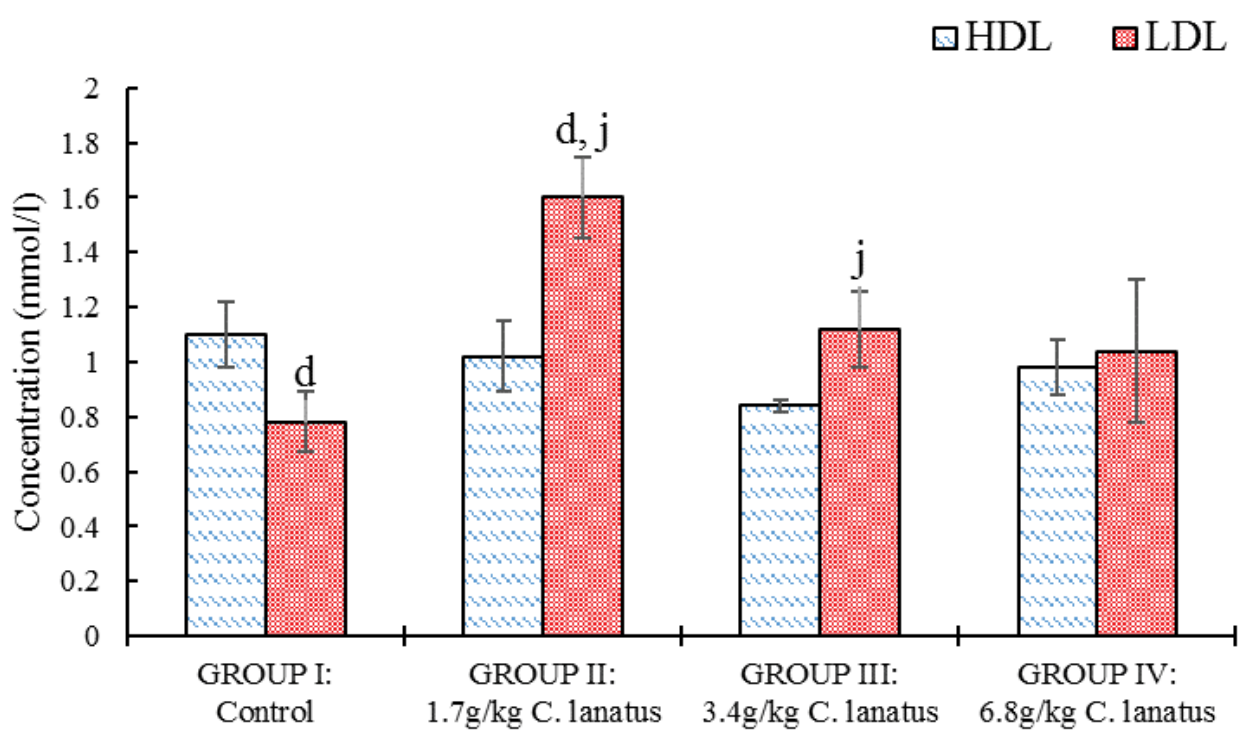

Figure 5: Serum HDL and LDL Albino (Wistar) Rats orally administered with a different dose of $C$. lanatus juices. Values are expressed as the mean \pm standard error $(n=5)$. Values with the same later are statistically significant at $P<0.05$.

$1.7 \mathrm{~g} / \mathrm{kg}$, while between the group administered $1.7 \mathrm{~g} /$ $\mathrm{kg}$ and that group administered $6.8 \mathrm{~g} / \mathrm{kg}$ there was a significant $(P<0.05)$ decrease in the LDL levels (Figure 5$)$.

In $\mathrm{LDH}$ levels there was a significant $(P<0.05)$ increase between the above-mentioned groups. The differences in HDL and cholesterol correlate significantly at $\mathrm{P}<0.05$ using Pearson's correlation coefficient. Also, the differences in cholesterol and LDL and then LDL and triglycerides showed strong significant correlation at $\mathrm{P}$ $<0.01$.

\section{Discussion}

Many studies demonstrated that when modifiable risk factors are treated and managed or corrected, the chances of CVD occurring can be greatly reduced. Evaluation of blood total cholesterol concentrations and other lipid abnormalities are part of a number of risk factors identified for cardiovascular diseases (CVD) [25]. Cardiovascular disease is the dominant single cause of premature mortality in the world [26]. Antioxidants, such as vitamin C and beta-carotene, are found in a variety of fruits and vegetables including watermelon and have been associated with lower levels of inflammation, oxidative stress, and CVDs markers. The result of this study shows that consumption of $C$. lanatus causes significant effects on some CVD risk biochemical markers in rats as reported elsewhere [27]. The decrease in the level of Creatine kinase with the higher concentration of $C$. lanatus suggests its cardioprotective potential which is supported by the work of Ahmed, et al. [28] in which lycopene was demonstrated to contribute to this effect. There was also the significant decrease in the levels of both triglycerides and LDL which conforms with the work of Collins, et al. [12] where the higher level of arginine from citrulline was shown to prevent excess accumulation of fat in fat cells due to the blocked ac- tivity of an enzymes called tissue non-specific alkaline phosphatase.

High serum LDL-C level was the most frequently occurring lipid profile abnormalities among hypertensive patients, followed by high levels of TC and TG. Low level of LDL-cholesterol is known to correlate with a low incidence of coronary heart disease, particularly arteriosclerosis. An increase of $1 \%$ cholesterol is reported to have resulted in a $3 \%$ increase in coronary heart disease. Equally a reduction in LDL-cholesterol by $2 \mathrm{mg} / \mathrm{dl}$ can result in $1 \%$ reduction in the risk for coronary artery disease [29]. Moreover, the significant decrease in sodium level as the dose of $C$. lanatus juice was increased suggests the significant relation between $C$. lanatus and blood pressure, since high sodium levels are associated with elevated blood pressure due to intravascular fluid retention [30]. Potassium, which is in the intracellular fluid, has been reported to be among the protective electrolytes against hypertension [31,32] showed no significant increase in this study. Lactate dehydrogenase (LDH), alanine aminotransferase (ALT) and aspartate aminotransferase (AST) in addition to cholesterol and triglyceride concentrations are demonstrated to be associated with cardiovascular risk factors [33,34] as has been the case in the current study. The results also showed that AST, TC, and HDL were not affected significantly by the consumption of $C$. lanatus fruit juice. Possibly, this is could be due to lower doses and short duration used. Hence larger doses and extended duration might have to be used to confirm these findings. It might also be due to some phytochemicals that naturally protect the integrity of biological membranes. The increase in the levels of sodium and LDL obtained at C. lanatus fruit juice dose of $1.7 \mathrm{~g} / \mathrm{kg}$ compared to the control might be due to the salt and then animal and vegetable protein contained in the diet given to the rats 
during the two weeks period before the investigations were done.

\section{Conclusion}

Numerous modifiable risk factors contribute to the increased risk for CVDs. These include dyslipidemia, hyperglycemia, obesity, and insulin resistance, lack of exercise, depression, and hypertension. In this study, Citrullus lanatus fruit and seeds juice significantly decreased the levels of triglycerides, serum creatine kinase, and serum sodium. These markers were implicated in CVDs when elevated. Hence the fruit could be said to have a cardiovascular risk factors reduction potential in normal albino rats.

\section{References}

1. Dariush Mozaffarian, Emelia J Benjamin, Alan S Go, Donna K Arnett, Michael J Blaha, et al. (2016) Heart disease and stroke statistics-2016 Update. Circulation 133: e38-e360.

2. Maton A (1993) Human biology and health. Englewood Cliffs, Prentice Hall, New Jersey, USA.

3. Mendis S, Puska P, Norrving B (2011) Global atlas on cardiovascular disease prevention and control. World Health Organization, Geneva, Switzerland.

4. Sharafedtinov KK, Plotnikova OA, Alexeeva RI, Sentsova TB, Songisepp E, et al. (2013) Hypocaloric diet supplemented with probiotic cheese improves body mass index and blood pressure indices of obese hypertensive patients--a randomized double-blind placebo-controlled pilot study. Nutr J 12: 138.

5. Roger W, Cate W (2007) Clinical pharmacy and therapeutics. ( $4^{\text {th }}$ edn), Churchill Livingstone Elsevier Limited, Philadelphia, PA, USA, 265-366.

6. Martin AC (2006) Clinical chemistry and metabolic medicine. ( $7^{\text {th }}$ edn), Edward Arnold Publishers Ltd, London, UK, 198-273.

7. Maahs DM, Daniels SR, de Ferranti SD, Dichek HL, Fly$\mathrm{nn} \mathrm{J}$, et al. (2014) Cardiovascular disease risk factors in youth with diabetes mellitus: A scientific statement from the American Heart Association. Circulation 130: 1532-1558.

8. Rodriguez CA (2016) The health potential of fruits and vegetables phytochemicals: Notable examples. Crit Rev Food Sci Nutr 56: 1097-1107.

9. Wu Y, Qian Y, Pan Y, Li P, Yang J, et al. (2015) Association between dietary fiber intake and risk of coronary heart disease: Ameta-analysis. Clin Nutr 34: 603-611.

10. Wang S, Moustaid-Moussa N, Chen L, Mo H, Shastri A, et al. (2014) Novel insights of dietary polyphenols and obesity. J Nutr Biochem 25: 1-18.

11. Charoensiri R, Konkachuichai R, Suknicom SU (2009) Beta-carotene, lycopene and alpha-tocopherol contents of selected Thai fruits. Food Chemistry 113: 202-207.

12. Collins K, Wu G, Perkins-Veazie P (2007) Watermelon consumption increases plasma arginine concentration in adults. Nutrition 23: 261-266.

13. Tilili I, Hdider C, Lenucci MS (2011) Bioactive compounds and antioxidant activities of different watermelon (Citrullus lanatus (Thunb.) Mansfeld) cultivars as affected by fruit sampling area. Journal of Food Composition and Analysis 24: 307-314.
14. Erifeta OG, Omage K, Esosa US, Njoya KH, Amegor OF, et al. (2011) Comparative evaluation of the antioxidant effect of watermelon and orange and their effects on some serum lipid profile of Wistar albino rats. International Journal of Nutrition and Metabolism 3: 97-102.

15. Abdelwahab S, Hassan LEA, Sirat HM (2011) Anti-inflammatory activities of cucurbitacin $E$ isolated from Citrullus lanatus var. citroides. Role of reactive nitrogen species and cyclooxygenase enzyme inhibition. Fitoterapia 82: 11901197.

16. Adesanya AO, Olaseinde OO, Ogutayo OO, Otulana JO, Adefule AK (2011) Effects of the methanolic extract of Citrullus lanatus seed on experimentally induced prostatic hyperplasia. European Journal of Medicinal Plants 1: 171-179.

17. Terri AE, Sesin PG (1958) Determination of serum potassium by using sodium tetraphenylboron. American Journal of Clinical Pathology 29: 86.

18. Maruna RFL (1958) Quantitative estimation of sodium ( $\mathrm{Na}$ ), potassium $(\mathrm{K})$ in human serum by colorimetric method. Clinical Chemistry Acta 2: 581-585.

19. Trinder $P$ (1951) A rapid method for the determination of sodium in serum. The Analyst 76: 596.

20. Trinder $P$ (1969) Enzymatic calorimetric determination of triglycerides by GOP-PAP method. Annal of Clinical Biochemistry 6: 24-27.

21. Lopes-virella MF, Stone P, Ellis S, Colwell JA (1977) Cholesterol determination in high-density lipoproteins separated by three different methods. Chemical Communications 23: 8823.

22. Reitman S, Frankel S (1957) A colorimetric method for the determination of serum glutamic oxalacetic and glutamic pyruvic transaminases. Am J Clin Pathol 28: 56-63.

23. Teco Diagnostics (2011) Sodium and Potassium Reagent (colorimetric method). Reagent kit, 1268N Lakeview Ave. Anaheim, CA 92807, USA.

24. Abbot B (1984) Creatine kinase. Clinical Chemistry. The C.V. Mosby Co. St. Louis, Toronto Princeton, 112-116.

25. Gethardt W, Waldenström J (1979) Creatine Kinase B-subunit in serum after immunoinhibition of M-subunit activity. Clinical Chemistry 25: 1274-1280.

26. Bell DSH (2000) Cardiovascular disease in South Asians. Lancet 356: 1108-1116.

27. Anand S, Yusuf S, Vuksan V, Devenesen S, Teo KT, et al. (2000) Differences in risk factors, atherosclerosis and cardiovascular disease between ethnic groups in Canada. The study of Health Assessment and Risk in Ethnic groups (SHARE). Lancet 356: 279-284.

28. Edward AJ, Vinyard BT, Wiley ER (2003) Consumption of watermelon juice increases the plasma concentration of lycopene and beta-carotene in humans. J Nutr 33: 10431050.

29. Ahmed MM, Ahmed AE, Amir DM, Gehan MM, Fahad AA (2012) Lycopene attenuates oxidative stress and hearts lysosomal damage in isoproterenol-induced cardiotoxicity in the rat: A biochemical study. Pathophysiology 19: 121-130.

30. (1984) The lipid research clinics coronary primary prevention trials results. 1: Reduction in the incidence of heart disease. JAMA 251: 351-364.

31. Gaddam KK, Nishizaka MK, Pratt UMN, Pimenta E, Aban I, et al. (2008) Resistant hypertension characterized by increased aldosterone levels and persistent intravascular volume expansion. Arch Intern Med 168: 1159-1164. 
32. Nurminen ML, Krepla R, Vapattalo H (1998) Dietary factors in the pathogenesis and treatment of hypertension. Annals of Medicine 30: 1433-1450.

33. Ascherio A, Rimm EB, Hernan MA, Giovannucci EL, Kawachi I, et al. (1998) Intake of potassium, calcium and fiber and risk of stroke among US men. Circulation 98: 1198-1204.
34. Amdt V, Brenner H, Rothenbacher D, Zschenderlein B, Fraisse E, et al. (1998) Elevated liver enzyme activity in construction workers. Prevalence and impact on early retirement and all-cause mortality. Int Arch Occup Environ Health 71: 405-412. 